\title{
Carta Xingu Vivo Para Sempre (2008)
}

Nós, representantes das populações indígenas, ribeirinhas, extrativistas, dos agricultores e agricultoras familiares, dos moradores e moradoras da cidade, dos movimentos sociais e das organizações não-governamentais da Bacia do rio Xingu, nos reunimos no Encontro Xingu Vivo para Sempre, realizado na cidade de Altamira (PA), entre os dias 19 e 23 de maio de 2008, para discutir, avaliar e denunciar as ameaças ao rio que nos pertence e ao qual pertencemos nós e reafirmar o modelo de desenvolvimento que queremos.

Nós, que somos os ancestrais habitantes da Bacia do Xingu, que navegamos seu curso e seus afluentes para nos encontrarmos; que tiramos dele os peixes que nos alimentam; que dependemos da pureza de suas águas para beber sem temer doenças; que dependemos do regime de cheias e secas para praticar nossa agricultura, colher os produtos da floresta e que reverenciamos e celebramos sua beleza e generosidade a cada dia que nasce; nós temos nossa cultura, nossa espiritualidade e nossa sobrevivência profundamente enraizadas e dependentes de sua existência.

Nós, que mantivemos protegidas as florestas e seus recursos naturais em nossos territórios, em meio à destruição que tem sangrado a Amazônia, nos sentimos afrontados em nossa dignidade e desrespeitados em nossos direitos fundamentais com a projeção, por parte do Estado Brasileiro e de grupos privados, da construção de barragens no Xingu e em seus afluentes, a exemplo da hidrelétrica de Belo Monte. Em nenhum momento nos perguntaram o que queríamos para o nosso futuro. Em nenhum momento nos ouviram sobre a construção de hidrelétricas. Nem mesmo os povos indígenas, que têm esse direito garantido em lei, foram consultados. Mesmo assim, Belo Monte vem 
sendo apresentada pelo governo como fato consumado, embora sua viabilidade seja questionada.

Estamos cientes de que interromper o Xingu em sua Volta Grande causará enchentes permanentes acima da usina, deslocando milhares de famílias ribeirinhas e moradores e moradoras da cidade de Altamira, afetando a agricultura, o extrativismo e a biodiversidade, e encobrindo nossas praias. Por outro lado, o barramento praticamente secará mais de 100 quilômetros de rio, o que impossibilitará a navegação, a pesca e o uso da água por muitas comunidades, incluindo aí várias terras e comunidades indígenas.

Também estamos preocupados com a construção de Pequenas Centrais Hidrelétricas (PCHs) nos rios formadores do Xingu. Algumas já foram construídas, outras já estão autorizadas e até hoje não houve qualquer tipo de avaliação dos impactos que esse conjunto de obras causará aos 14 povos indígenas do Parque Indígena do Xingu. Essas barragens profanam seus sítios sagrados e podem acabar com os peixes dos quais se alimentam.

Assim, nós, cidadãos e cidadãs brasileiras, vimos a público comunicar à sociedade e às autoridades públicas federais, estaduais e municipais a nossa decisão de fazer valer o nosso direito e o de nossos filhos e netos a viver com dignidade, manter nossos lares e territórios, nossas culturas e formas de vida, honrando também nossos antepassados, que nos entregaram um ambiente equilibrado. Não admitiremos a construção de barragens no Xingu e seus afluentes, grandes ou pequenas, e continuaremos lutando contra o enraizamento de um modelo de desenvolvimento socialmente injusto e ambientalmente degradante, hoje representado pelo avanço da grilagem de terras públicas, pela instalação de madeireiras ilegais, pelo garimpo clandestino que mata nossos rios, pela ampliação das monoculturas e da pecuária extensiva que desmatam nossas florestas.

Nós, que conhecemos o rio em seus meandros, vimos apresentar à sociedade brasileira e exigir das autoridades públicas a implementação de nosso projeto de desenvolvimento para a região, que inclui:

1. A criação de um fórum de articulação dos povos da bacia que permita uma conversa permanente sobre o futuro do rio e que 
possa caminhar para a criação de um Comitê de Gestão de Bacia do Xingu;

2. A consolidação e proteção efetiva das Unidades de Conservação e Terras Indígenas bem como o ordenamento fundiário de todas as terras públicas da região da Bacia do Xingu.

3. A imediata criação da Reserva Extrativista do Médio Xingu.

4. A imediata demarcação da TI Cachoeira Seca, com o assentamento digno dos ocupantes não indígenas, bem como a retiradas dos invasores da TI Parakanã.

5. A implementação de medidas que efetivamente acabem com o desmatamento, com a retirada de madeira ilegal e com a grilagem de terras.

6. O incremento de políticas públicas que incentivem o extrativismo e a consolidação da agricultura familiar feita em bases agroecológicas e que valorizem e estimulem a comercialização dos produtos da floresta.

7. Efetivação de políticas públicas capazes de promover a melhoria e instalação de sistemas de tratamento de água e esgoto nos municípios.

8. O incremento de políticas públicas que atendam as demandas de saúde, educação, transporte, segurança, adequadas às nossas realidades.

9. Desenvolvimento de políticas públicas que ampliem e democratizem os meios de comunicação social.

10. O incremento de políticas públicas para a ampliação das experiências de recuperação de matas ciliares e de áreas degradadas pela agropecuária, extração de madeira e mineração.

11. Que nenhum outro dos formadores do Xingu venha a ser barrado, como já aconteceu ao rio Culuene com a implantação da PCH Paranatinga II. 
12. Proteção efetiva do grande corredor de sóciobiodiversidade formado pelas terras indígenas e unidades de conservação do Xingu.

Nós, os que zelamos pelo nosso rio Xingu, não aceitamos a invisibilidade que nos querem impor e o tratamento desdenhoso que o poder público tem nos dispensado. Nos apresentamos ao País com a dignidade que temos, com o conhecimento que herdamos, com os ensinamentos que podemos transmitir e o respeito que exigimos.

Esse é o nosso desejo, essa é a nossa luta. Queremos o Xingu vivo para sempre.

Altamira, 23 de maio de 2008.

Assinam: Kayapó da Aldeia Kriny, Kayapó do Bacajá Xikrin, Kayapó de Las Casas, Kaiapó de Gorotire, Kayapó Kubenkrãkênh, Kayapó Moikarakó, Kayapõ Pykarãrãkre, Kayapó Kendjâm, Kayapó Kubenkàkre, Kayapó Kararaô, Kayapó Purure, Kayapó Tepore, Kayapó Nhàkin, Kayapo Bandjunkôre, Kayapó Krânhãpari, Kayapó Kawatire, Kayapó Kapot, Kayapó Metyktire, Kayapó Piaraçu, Kayapó Mekrãnoti, Kayapó Pykany, Kayapó da Aldeia Aukre, Kayapó da Aldeia Kokraimoro, Kayapo Bau, Kayapó Kikretum, Kayapó Kôkôkuêdja, Mrotidjam Xikrin, Potikrô Xikrin, Djudjekô Xikrin, Cateté Xikrin, Ôodja Xikrin, Parakanã da aldeia Apyterewa e Xingu, Akrãtikatejê, Parkatejê, Munduruku, Araweté, Kuruwaia, Xipaia, Asurini, Arara da aldeia Laranjal e Cachoeira Seca, Arara do Maia da terra Alta, Panará, Juruna do Km 17,Tembé, Kayabi, Yudja, Kuikuro, Nafukua, Kamaiurá, Kalapalo, Waurá, Trumai, Xavante, Ikpeng, Apinayé, Krahô, Associação das Mulheres Agricultoras do Assurini, Associação de Mulheres Agricultoras do Setor Gonzaga, Associação dos Moradores do Médio Xingu, Associação dos Moradores da Resex do Iriri ,Associação dos Moradores da Resex Riozinho do Anfrisio, AFP- Associação Floresta Protegida do povo Kayapó, Associação Indígena Kisedje - povo Kisedje (Parque Indígena Xingu), 
Associação Pró-Moradia do Parque Ipê, Associação Pró-Moradia do São Domingos, Associação Yakiô Panará - Povo Panará, Associação Yarikayu - povo Yudja (Parque Indígena Xingu), Articulação de Mulheres Paraenses, Articulação de Mulheres Brasileiras, ATIX - Associação Terra Indígena Xingu (Parque Indígena Xingu), CJP- Comissão de Justiça e Paz, Conselho Indigenista Missionário (CIMI), Prelazia do Xingu, CPT- Comissão Pastoral da Terra, FAOR - Fórum da Amazônia Oriental, Federação de Assistência Social e Educacional (FASE), FETAGRI- Federação dos Trabalhadores na Agricultura Regional Altamira, Fórum de Direitos Humanos Dorothy Stang (FDHDS), Fórum Popular de Altamira, Fundação Elza Marques, Fundação Tocaia, Fundo DEMA, Grupo de Mulheres do Bairro Esperança, Grupo de Trabalho Amazônico Regional Altamira (GTA), IPAM- Instituto de Pesquisa Ambiental da Amazônia, Coordenação das Organizações Indígenas da Amazônia Brasileira (COIAB), MAB- Movimento dos Atingidos por Barragem, STTR-Altamira, Pastoral da Juventude, S.O.S. Vida, Sindicato das Domésticas de Altamira, Sindicato dos Trabalhadores em Educação Pública do Pará - SINTEPP, Movimento de Mulheres Trabalhadoras de Altamira Campo e Cidade - MMTACC, Movimento de Mulheres do Campo e Cidade do Pará - MMCC, Movimento de Mulheres do Campo e Cidade Regional Transamazônica e Xingu, Fórum de Mulheres da Amazônia Paraense, SDDH-Sociedade Paraense dos Direitos Humanos, MNDH- Movimento Nacional dos Direitos Humanos, MMMMovimento de Mulheres Maria Maria, SOS Corpo, Instituto Feminista para a Democracia, Instituto Socioambiental - ISA, Fundação Viver Produzir e Preservar (FVPP).

Apoio: Fundação Heinrich Boell, International Rivers, Rainforest Foundation, Rainforest Noruega 